A 62-year-old woman with a history of abdominal surgery (hysterectomy and appendectomy) underwent a colonoscopy because of changes in intestinal habits. The colonoscope was passed into the cecum without difficulty, with the patient under conscious sedation (midazolam plus pethidine). There were no pathological findings. Some 4 hours later the patient complained of abdominal pain and distension. Plain abdominal radiography disclosed distended loops of small and large bowel filled with gas (Figure $\mathbf{1}$ ). Erect abdominal radiography showed airfluid levels at the small bowel (Figure 2). A diagnosis of dynamic ileus following colonoscopy with the use of pethidine was made and conservative management was adopted. At 48 hours after colonoscopy, the abdominal pain worsened and there was generalized tenderness. An urgent laparotomy was performed. There were small-bowel adhesions at a McBurney incision site in which a loop of small bowel had become trapped. Proximal to the ob-

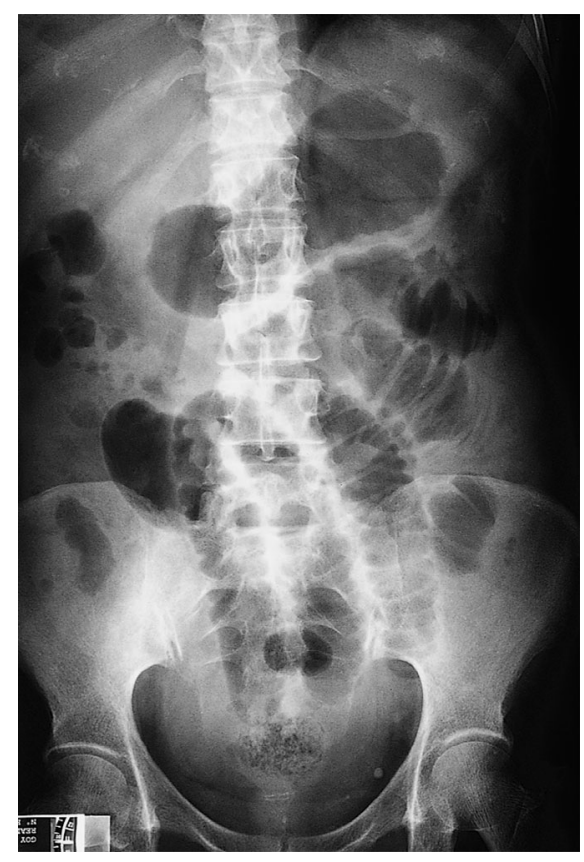

Figure 1 A plain abdominal radiograph showing distended loops of small and large bowel filled with gas.

\title{
Small Bowel Obstruction and Perforation after Colonoscopy
}

struction there was a small perforation of the dilated loop.

In the literature, small-bowel obstruction after colonoscopy which was caused by adhesions has been described in very few cases [1], whereas small bowel dynamic ileus after colonoscopy with pethidine sedation has been found more frequently [2-4]. In three recently reported cases of small-bowel obstruction after colonoscopy, only one was confirmed at laparotomy, the two other patients being managed conservatively [1]. Our patient did not respond to conservative management, and 48 hours after colonoscopy she developed generalized abdominal tenderness, absence of bowel sounds and a raised white blood cell count. She had not previously experienced symptoms related to smallbowel occlusion due to adhesions. The manipulation associated with passing the scope into the cecum and air insufflation through the ileocecal valve may be responsible for the entrapment of small

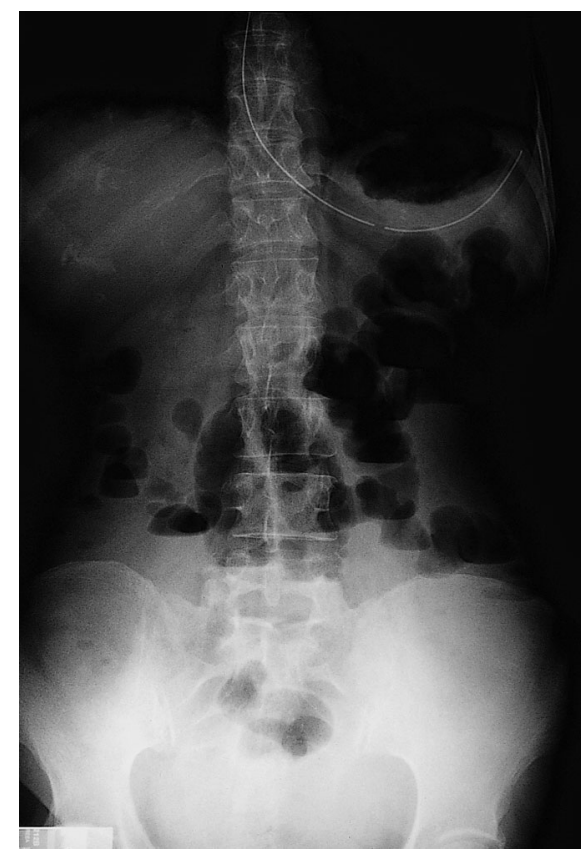

Figure 2 An erect abdominal radiograph showing air-fluid levels at the small bowel. Note the loop, probably trapped by adhesions, in the middle of the lower abdomen. bowel by adhesions for the first time in a previously asymptomatic patient $[1,2]$. To our knowledge, this is the first report of the development of small bowel obstruction due to adhesions and subsequent intestinal perforation, after a normal colonoscopy.

\section{A. González Ramírez, S. Ávila, \\ L. López-Rosés, A. Lancho, E. Santos, S. Soto, S. Penín}

Digestive Diseases Unit, Department of Internal Medicine, Hospital Xeral Lugo, Lugo, Spain

\section{References}

${ }^{1}$ Malki SA, Basset ML, Pavli P. Small bowel obstruction caused by colonoscopy. Gastrointest Endosc 2001; 53: 120-121

2 Wallner M, Allinger S, Wiesinger H. et al Small bowel ileus after diagnostic colonoscopy. Endoscopy 1994; 26: 29

${ }^{3}$ Ramakrishnan T. A dynamic ileus complicating colonoscopy. South Med J 1979; 72: 92 - 93

${ }^{4}$ Meyers MA, Ghahremani GG. Complications of gastrointestinal fiberoptic endoscopy. Radiology 1977; 2: 273 - 280

\section{Corresponding Author}

\section{A. González Ramírez, M.D.}

Digestive Diseases Unit

Department of Internal Medicine Hospital Xeral Lugo

C/Campos Novos 117, $4^{\circ} \mathrm{L}$ 27002 Lugo

\section{Spain}

Fax: + 34-982-296613

E-mail: seanlugo@hotmail.com 